\title{
The Influential Factors of Employees' Innovative Behavior and the Management Advices
}

\author{
Xiangyin Li, Yishuang Zheng \\ Management School, Jinan University, Guangzhou, China \\ Email: a3yishuang0304@126.com
}

Received 2 October 2014; revised 25 October 2014; accepted 18 November 2014

Copyright (C) 2014 by authors and Scientific Research Publishing Inc.

This work is licensed under the Creative Commons Attribution International License (CC BY). http://creativecommons.org/licenses/by/4.0/

(c) (i) Open Access

\begin{abstract}
In order to obtain and maintain a competitive advantage on the vagaries of the ecological environment, the organizations must innovate continuously. There is no doubt that the employees are the main force for the organizations, and their innovative behaviors are vital for innovation performance of an organization. Therefore, the organizations have to take measures to stimulate the innovation willingness of employees and promote their innovation behavior. Based on the relevant research results, this paper sums up the main factors affecting employees' innovative behavior including organizational commitment, psychological capital on the individual level, and organizational innovation atmosphere, leadership, social capital, work characteristics on the organizational level. In the end, the paper makes proposals for employees' innovative behavior management.
\end{abstract}

\section{Keywords}

Employees' Innovative Behavior, Influential Factors, Management Suggestion

\section{Introduction}

With the rapid development of knowledge economy and the constantly updating of science and technology, almost all organizations have to face with an uncertain dynamic environment which brings enormous risks and competitive pressures. In order to gain competitive advantage, organizations must rely on employees to innovate in processes, methods and operations (Shalley \& Gilson, 2004) [1]. The so-called innovation, refers to the individual to produce novel, practical and valuable products, processes, methods and ideas to the organization (Zhou \& Shalley, 2003), which is the interaction of the social context and individual personal characteristics(Woodman, 
et al., 1993) [2].

Employees are the main driving force of innovation, and their innovation behavior is paid more and more attention. How to fully promote more innovative behavior of employees has become a challenge to many scholars and entrepreneurs. So far, many scholars have done some research on employee innovation behavior and influencing factors, but they pay more attention on some certain unilateral effects, such as the impact of the leader, the impact of organizational innovation atmosphere (Gu Yuandong, et al., 2010) [3]. There is the lack of a comprehensive study of factors affecting employee innovation behavior. For that, this paper will explore factors of employee's innovative behavior base on previous research, trying to provide a theoretical reference for employee's innovative behavior management, and propose appropriate management recommendations.

\section{Concept of Employee Innovation Behavior}

Innovative behavior is an act of generating, promoting and application of innovative thinking in the organization for the purpose of personal and organizational performance, which enables employees to use innovative ways of thinking, quickly and accurately respond to customer demand changes (Scott, Bruce, 1994; Woodman, et al., 1993; Robert, 2001) [2] [4]. Kleysen and Street (2001) divided individual innovative behavior into five stages, including looking for opportunities, generating ideas, research supporting, and applications by the 289 individual innovative behaviors involved in 28 literatures. For that, Huang Zhikai (2004), Lu Xiaojun (2007) and others have tested it with the actual situation, and the employee's innovative behavior is defined as: In the work process, employees generate innovative ideas or solutions to problems, and efforts will be paid to the practice [5] [6]. The motivation of employee's innovative behavior can be divided into internal and external factors. Internal factors refer to innovative personal traits and ability to participate in innovation, and external factors including the open team environment, the support of leaders. Under the mutual working of internal and external factors, the innovative efficacy and creative willingness of employees have been improved. (Yang Jingzhao, et al., 2011) [7].

\section{Factors Affecting Employees' Innovative Behavior on the Individual Level}

\subsection{Organizational Commitment}

In order to obtain working outcome from employees, the organization provides employees with a variety of resources, and the employees establish a personal commitment to the organization depend on what they get from the organization. Organizational commitment refers a kind of mental state which employees are willing to maintain membership in organizations, showing the purposes of the employees why stay working. According whether these purposes and the interests, the targets of the organization are consistent, it can be divided into positive emotional commitment and negative continual commitment.

King $(1995,2002)$ pointed out that employees who highly agree with the values and ideas of the organization and love the job are the conditions of actively innovation behavior produced. Janssen (2000) argues that psychological contract employees perceived which means their organizational commitment level, determines whether they engaged in innovation activities. Emotional commitment generated by the internal motivation of individual will be beneficial for employees to improve the efficiency of learning and working, and to make more fully use of their own creativity. Conversely, in the case of the continued commitment which formed in consideration of the cost of quit, fewer individual will take initiative innovation. In a word, the positive emotional commitment of individual is an important prerequisite to promote innovative behavior of employees (Tao Youmei, et al., 2012) [8].

\subsection{Psychological Capital}

Psychologically speaking, employees are willing to take the risk of innovation failure and actively participate in innovation, which are closely related to their psychological characteristics. The employees with more psychological capital will have more innovative behavior (Han Yi, et al., 2011) [9]. Individual psychological capital is a state which means positive psychological developing, including: 1) self-efficacy (confidence); 2) optimism; 3) hope; 4) toughness (Luthans \& Avolio, 2003) [10]. Sweetman et al. (2010) found that there is a significant positive relationship between all of these variables and employees' creativity after respectively inspection [11].

In fact, much more scholars have studied on self-efficacy. Tierney et al. (2002) creatively proposed "innovative self-efficacy", which is, individuals with specific tasks evaluate their ability and confidence of innovation, 
showing the belief or expectations of their own innovative performance [12]. Creative self-efficacy is positively related to employees' innovation. In the Chinese context, creative self-efficacy is the foundation and key individual factors to promote employees' innovative behavior, and it can affect the level of effort of individual activities, as well as stamina and endurance in the face of setbacks and failure (Gu Yuandong, et al., 2010, 2011) [3] [13].

Innovation could not achieve the outcomes or high rates of return desired, so it does require not only strong willpower, but also optimistic attitude, full of hope for innovation and firm determination. Optimistic individuals whose self-expectations are positive often have the feeling of controlling over their own destiny, and innovative behaviors are easier to generate. Hopeful employees also often have independent, free thought and strong creativity. Employees with toughness would have stronger stress tolerance, and they do not easily give up in the face of an uncertain environment and solve the problems creatively (Sweetman, et al., 2010) [11].

\section{Factors Affecting Employees' Innovative Behavior on the Organizational Level}

\subsection{Organizational Innovation Atmosphere}

The organizational innovation atmosphere is defined by Amabile (1996) as the perception description that the degree of supporting for creativity and innovation felt by members of the organization on the work environment [14]. It reflects the perception of the individual about whether the organization provide environment which is conducive learning and innovation, and its degree. And it's the system reflection of individual and environment, determining innovation level of the individual and the organization (Tao Yongmei, 2012) [8]. Organizational innovation atmosphere including the concept of advocacy, market guidance, evaluation and incentive, training, communication and cooperation, resource guarantee, model, authorization (Ma Yueting, 2009) [15], will directly affect the employee's innovative behavior, capability and performance organization though attitudes, beliefs, motivations and values of members of the organization. Psychological capital plays an intermediary role in the relationship between the organizational innovation atmosphere and employee innovative behavior (Zhen Meirong, et al., 2012) [16]. Lian Xins' (2013) empirical research shows that organizational innovation atmosphere has a direct effect on individual innovative behavior [17].

\subsection{Leadership}

Employees' innovative behaviors depend on not only the cognitive style, intrinsic motivation, psychological capital, but also the effective stimulation from the external environment, especially the leadership and motivation (Mumford, et al., 2002). Communication is the main way that leaders transfer the management concept to the employees and effects employees' behavior, which is more useful than other forms of communication (Wang Yongyue, 2014) [18]. Leadership improves employees' innovative behavior through direct encouragement or setting the goal of innovation for employees, (Wang Duanxu, et al., 2010) [19]; and also can rapidly capture the subordinates emotional information, do evaluation and praise, to show their support and admiration for employees' innovation.

\subsection{Social Capital}

Madjar (2005) believes that creativity is not the results of organizational members' independent thinking, but produces in the frequently interaction process between members [20]. Interaction may promote emotional reciprocity and trust between the members which is not only conducive for employees to share learning experience and technology knowledge, but also broaden field of vision, promote new ideas, and generate new ideas (Yang \& Chen, 2005) [21]. Lin Zifen (2013) also believes the employees who are willing to share knowledge with others will increase their knowledge reserve and more likely produce the innovation behavior [22].

The relationship between the customers and employees also will have an impact on the employees' innovative behavior. The communication with customers, on one hand, can make the employees understand the different characteristics, needs and service development trend more easily. On the other hand, it can improve their stock of knowledge and develop creative thinking, promote greater employee's innovative behavior.

\subsection{Work Characteristics}

Employees' innovative behavior is also related with employees' work experience and job characteristics. First of 
all, the related working experience would influence employees’ innovative behavior. Employees who are familiar with the tasks would easily find working tips, overcome the fear of innovation failure, and be more confident when innovating (Ericsson, et al., 1993). Secondly, because of the need to break formulary thinking in the complex work, employees have to learn and solve the new arising problems continuously, so that they would have the profound sense of innovation and high level innovative skills. Thirdly, the working routine degree would influent employee innovative behavior. At the high rates of routine and repetition, employees who often work according to the rules would form a solidified thought, and their innovation intention is very low and very difficult to promote the innovative behavior.

\section{Conclusion and Suggestions}

From the above analysis, innovative behavior is affected not only by the employee's commitment and individual's psychological capital, but also by the organizational innovation atmosphere, leadership, social capital and work characteristics. Based on this, this paper puts forward the following suggestions for the employees' innovative behavior management:

Firstly, the organization should pay more attention on whether personal characteristics and the organizational traits are matching when recruiting. Characteristic is a long-term of behavior model, and organizations have to spend a lot of human, material resources when they want to make them change. Therefore, when recruiting, organizations should select employees who would face various challenges actively, and hold innovation consciousness and ability, rather than changing the employees' characteristics to adapt to the organization's [23].

Secondly, the organization should focus on the publicity and advocacy of organization internal innovation culture and innovation concept. In addition, the organization can use training, promotion, authorization, goal orientation so as to encourage employees' innovative behavior.

Thirdly, the organizations should pay more attention to social capital, including the relationship between superior and subordinate, the relationship among ordinary employees, and the relationship between employees and customers. The individual behavior intention is influenced by the organization atmosphere, so that employee will actively innovate if thought they are in a fair, friendly, encouraging innovation atmosphere, (Wang Shihong, et al., 2013) [24]. In order to encourage employee innovative behavior, leaders should pay more attention to emotional information from subordinates and make a corresponding response in the process of innovation. The organization can adopt development, training and other activities to assist employees to establish trust relationship to promote information and knowledge sharing. Organizations also should encourage employees to establish a good relationship with customers for better innovation.

\section{References}

[1] Shalley, C.E., Zhou, J. and Oldham, G.R. (2004) The Effects of Personal and Contextual Characteristics on Creativity: Where Should We Go from Here? Journal of Management, 30, 933-958. http://dx.doi.org/10.1016/j.jm.2004.06.007

[2] Woodman, R.W., Sawyer, J.E. and Griffin, R.W. (1993) Toward a Theory of Organizational Creativity. Academy Management Review, 18, 293-321.

[3] Gu, Y.D. and Peng, J.S. (2010) The Effects of Organizational Innovation Climate on Employee Innovative Behavior: The Mediating Role of Creative Self-Efficacy. Nankai Business Review, 1, 30-41.

[4] Scott, S.G. and Bruce, R.A. (1994) Determimants of Innovative Behavior: A Path Model of Individual in the Workplace. Academy of Management Journal, 37, 580-670. http://dx.doi.org/10.2307/256701

[5] Huang, Z.K. (2004) The Study of Relationship between Organizational Innovative Climate Perception, Individual Innovation Behavior, Self Efficacy Perception and the Type to Solve the Problem-Taking the Banking Industry as the Research Object. Ph.D. Thesis, Institute of Human Resource Management, National Sun Yat-sen University, Gushan.

[6] Lu, X.J. and Zhang, G.L. (2007) The Study of the Work Motivation Effect on Individual Innovation Behavior. Soft Science, 21, 124-127.

[7] Yang, J.Z., Yang, D.T., Zhao, S.D., et al. (2011) The Inner Driving Force of Employees’ Innovation in the Workplace: Employees’ Creativity Self-Efficacy. Psychological Science Progress, 9, 1363-1370.

[8] Tao, Y.M. and Kang, Y. (2012) The Relationship Study Based on the Organizational Commitment between Organizational Innovation Climate and Individual Innovation Behavior. Industrial Technology and Economy, 6, 145-150.

[9] Han, Y. and Yang, B.Y. (2011) Authentic Leadership, Psychological Capital and Employee Innovative Behavior: The Moderating Role of Exchange of Leaders Member. Management World, 12, 78-86. 
[10] Luthans, F. and Avolio, B.J. (2003) Authentic Leadership: A Positive Developmental Approach. In: Cameron, K.S., Dutton, J.E. and Quinn, R.E., Eds., Positive Organizational Scholarship, Barrett-Koehler, San Francisco, 241-261.

[11] Sweetman, D., Avey, J.B. and Luthans, F. (2010) Relationship between Positive Psychological Capital and Creative Performance. Canadian Journal of Administrative Sciences, 28, 4-13.

[12] Tierney, P. and Farmer, S.M. (2002) Creative Self-Efficacy: Its Potential Antecedents and Relationship to Creative Performance. Academy of Management Journal, 45, 1137-1148. http://dx.doi.org/10.2307/3069429

[13] Gu, Y.D. and Peng, J.S. (2011) The Mechanism Study of the Creativity Self-Efficacy Sense Impact on Employee Innovative Behavior. The Management of Scientific Research, 9, 63-73.

[14] Amabile, T.M., Conti, R., Coon, H., et al. (1996) Assessing the Work Environment for Creativity. Academy of Management Journal, 39, 1154-1184. http://dx.doi.org/10.2307/256995

[15] Ma, Y.T. (2009) The Impact Mechanism Study of Chinese Enterprise Organizational Innovative Atmosphere Construction Effects on the Innovation Behavior. Ph.D. Thesis, Economic Management Institute of Tsinghua University, Beijing.

[16] Mei, R.Z., Peng, J.S. and Yang, J.Z. (2012) The Analysis of Organizational Innovation Climate Effect on Employee Innovative Behavior: Based on Individual Goal Orientation, Psychological Capital. Technology and Economy, 1, 86-90.

[17] Lian, X., Yang, B.Y. and Ma, Y.T. (2013) The Study of Organizational Innovation Climate Influence on Employee Innovative Behavior. Journal of Management (CHINA), 7, 985-992.

[18] Wang, Y.Y. and Duan, J.Y. (2014) The Influence of Human Resource Practices on Employee Innovative Behavior: The Mediating Role of Psychological Contract Breach and the Regulating Role of Communication between Leaders and Employees. Psychological Science, 1, 172-176.

[19] Wang, D.X. and Hong, Y. (2010) The Mechanism Study of Leaders' Support Promotes Employees' Creativity. Nan Kai Business Review, 4, 109-114.

[20] Madjar, N. (2005) The Contributions of Different Groups of Individuals to Employees' Creativity. Advances in Developing Human Resources, 7, 182-206. http://dx.doi.org/10.1177/1523422305274525

[21] Yang, J. and Chen, C. (2005) Systemic Design for Improving Team Learning Climate and Capability: A Case Study. Total Quality Management \& Business Excellence, 16, 727-740. http://dx.doi.org/10.1080/14783360500077658

[22] Lin, Z.F. and Sun, R. (2013) Internal Social Capital Impacts on Employee Innovative Behavior: Based on the Mediating Role of Knowledge Sharing. East China Economic Management, 12, 55-58.

[23] Liu, S.Z. (2011) The Mechanism Study That Customer Demand Changing Influences on Employee Innovative Behavior. Science Research, 8, 1258-1265.

[24] Wang, S.H., Xu, B. and Peng, J.S. (2013) The Effects of Organizational Climate Awareness on Employee Innovative Behavior: Based on the Intermediary Effect of Knowledge Sharing Intention. Science Research Management, 5, 130 135. 
Scientific Research Publishing (SCIRP) is one of the largest Open Access journal publishers. It is currently publishing more than 200 open access, online, peer-reviewed journals covering a wide range of academic disciplines. SCIRP serves the worldwide academic communities and contributes to the progress and application of science with its publication.

Other selected journals from SCIRP are listed as below. Submit your manuscript to us via either submit@scirp.org or Online Submission Portal.
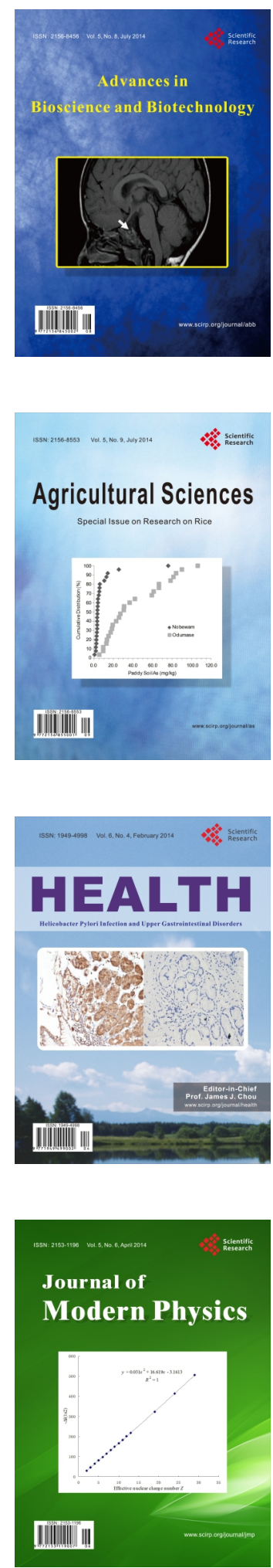
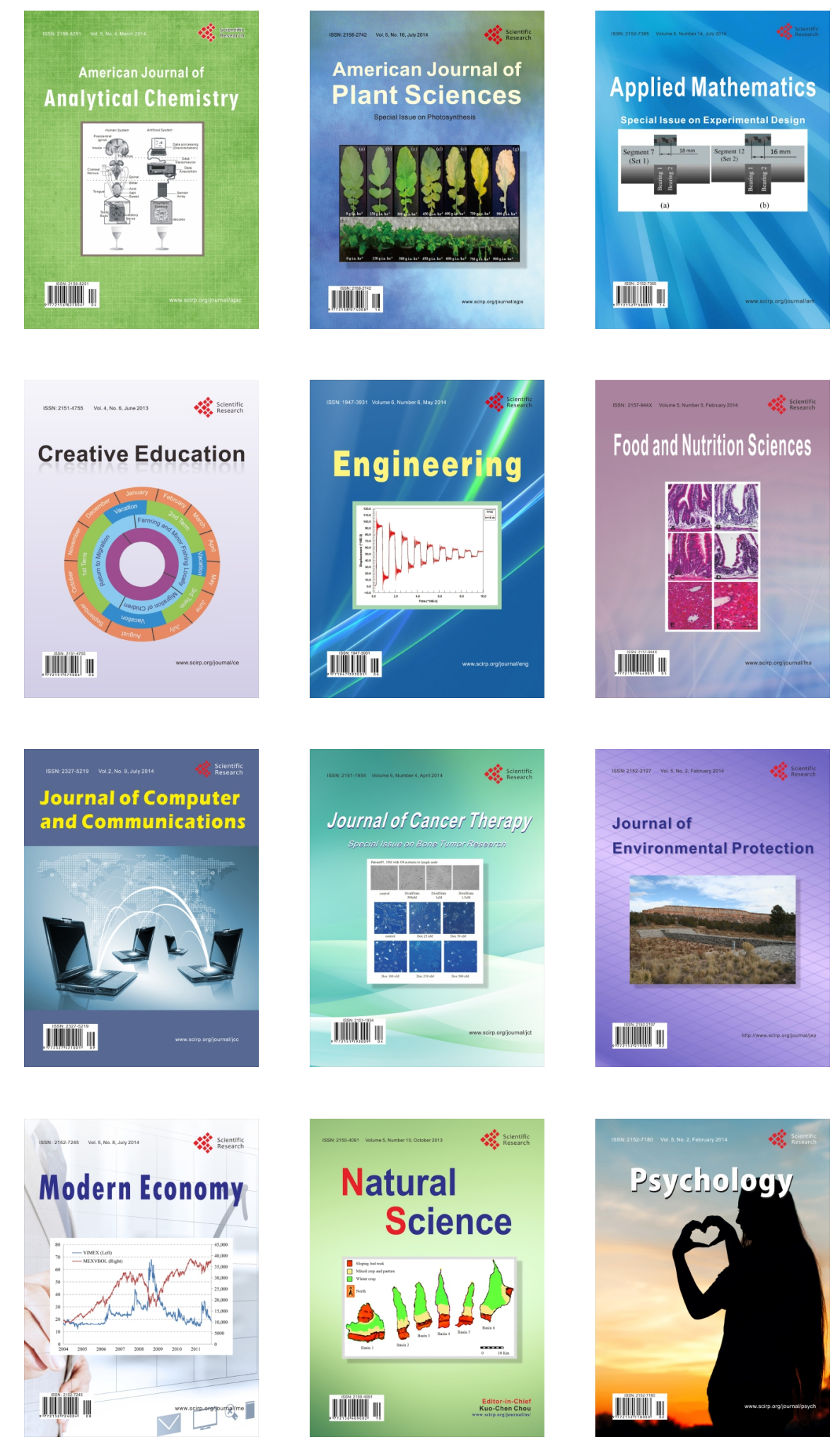